\title{
Build Practice Mode in a Professional Art and Design Workshop Classroom
}

\author{
Zhaoying XIANG \\ Department of Fine Art \\ Sichuan University for Nationalities \\ Kangding,626001 China
}

\begin{abstract}
This workshop is a professional art and design practice pattern in professional development, classroom teaching, thinking training, ability to communicate, collaboration and creation, inspiring individuals to participate in practice, inspiring the enthusiasm of the proposed features consistent with current large design education and cultural power strategy effective classroom teaching mode. In the Ministry of Education, it inspires student to actively explore, discuss, under the guidance of participation, issues of art and design education needs to change the form of faces, the workshop model into practice classroom teaching art and design professionals to help improve teaching practice system, help to develop students 'practical ability to help improve students' ability to innovate. We should propose the establishment of professional art and design strategy workshop practice patterns and building frameworks, and models constitute a recommendation as to provide some ideas for art and design education practice mode.
\end{abstract}

Keywords- Workshop; Art and Design; Professional Practice

\section{INTRODUCTION}

Workshop has targeted, open-minded, active atmosphere, focused practice, unity and cooperation to create features, art and design professionals at different levels of classroom teaching universities that also have these characteristics in varying degrees. Art and design in professionals' classroom workshops are to introduce the practice mode, which aims to organize classroom teaching through effective initiative to boost student learning from each other. So that students and teachers can participate in practice and exploration, to stimulate students' creative thinking, to promote art and design professional theory, the concept of development, to provide effective protection for the students to enter society organizations design, studio design, company design. Compared to traditional classroom teaching, classroom workshops teaching mode are new, lively, open, permeated with practicality, collaborative, joyful generation and creativity. [1] Despite the professional art and design relative to other professional, classroom appears to be focused on operational and practical, but students are still unable to accurately locate you in the process of learning, find their weaknesses and advantages. As a designer, he should have full of knowledge, ability to learn, the ability to communicate that is essential, practical workshops teaching model that can help students understand their own characteristics, opportunities to avoid weaknesses. They should not only learn the knowledge, but also in their own professional learning process to expand their horizons, and accumulate experience. In the current social recruitment process, many companies require students to have the experience of a year or even longer. So the students also complained to the teacher, they said: "The company required us to have two years of relevant experience," "wages too low to work out." It seems to embody the invisible school of art and design education and social dislocation. So how can we change this situation? It also reflects the importance of building workshop practice patterns. [2012] on the 4th Department of Education to teach high "number of opinions on the Ministry of Education to improve the overall quality of higher education," it pointed out: to colleges and universities, They should be encouraged to explore the scientific basis, practical skills and cultural literacy training model convergence. With the reform of teaching management, exploration under the guidance of teachers, students choose professional, independent choices of courses and other independent learning modes. We should have innovative teaching methods, advocacy heuristic, inquiry, discussion, participatory teaching. [2] Therefore, the introduction of professional art and design workshop approach in line with the large classroom design conditions facing our country. It should be in line with the university classroom teaching art and design professionals since college enrollment in the face of many students in each class, students practice and create capacity than weak situation. [3]

\section{Establish a Professional ART AND DESIGN THE PRACTICE MODE OF STRATEGY WORKSHOP}

Bauhaus (Bauhaus, 1911-1937) has called the 20th century's most influential art institutions and the most controversial, it creates educational philosophy of modern design, which is made irrefutable arts education theory and practice excellence. [4] It is among the arts, crafts and education to find a meeting point, the balance point and innovation. Bauhaus education "both technology and art," 
and "Factory apprenticeship" is the Bauhaus School student interaction, design practice and teaching content together to complete a good system. So what we can learn from the experience? What is in common between the teaching philosophy of art and the Bauhaus School of Design Workshop? In the culture of this strategy, the design of modern and contemporary art college classroom teaching ideas is on how professional development to promote innovation and continuous optimization of modern teaching methods, how the way to overcome the homogeneity of college and professional art and design construction. [5] Thus, professional art and design workshops are to reflect the cultural characteristics of the development, professional development, geographic environment, technological development and specific projects and other innovative ideas; we should establish and improve the overall environment workshop approach (Figure 1).

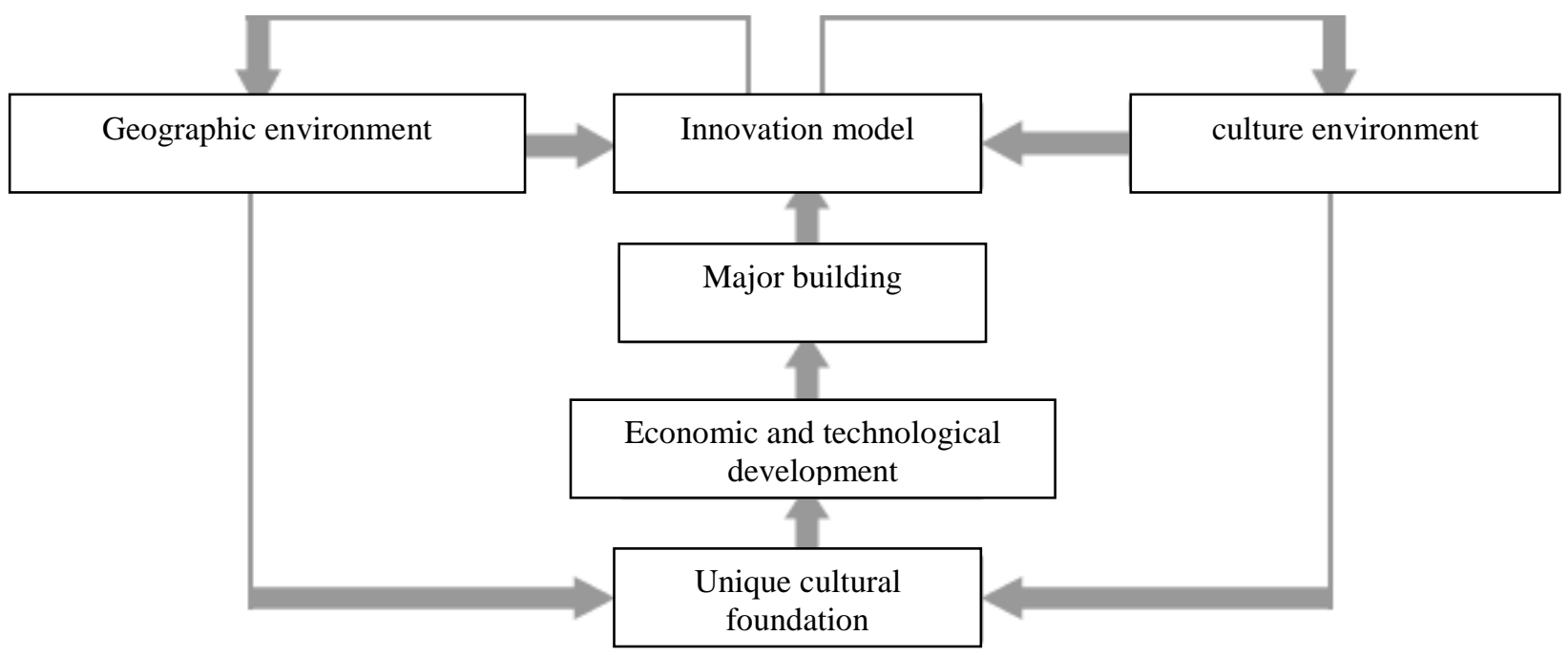

Figure 1 workshop to promote innovation model system constitutes

Bauhaus teaching system melts technology, art, and become the core of economic integration that has become an independent professional design institution. Workshop is the main venue and the way of teaching, so that students and teachers get together to discuss specific issues and practices, while designing production, and social integration, the product sold, which is transformed into a combination of design and technology economy. This model allows students, teachers must have to explore, study spiritual, economic and design collision itself, while allowing students to accept new knowledge, new technology, new materials and other aspects of a more proactive, more conscious. Specific characteristics of the Bauhaus workshop practice for the practice of art education not only advocate and social realities, but during the professional art and design students throughout the education and training process should reflect its educational system of professional practice mode. On the one hand, according to incomplete statistics, China is to set up a professional art and design colleges are more than 1400, the number of graduates each year is about 10 million, in the face of such a large number of development, China needs our design education thinking. [6] a large number of students will inevitably lead to teaching overload phenomenon that appears to run a larger number of teachers teaching hours, overwhelmed; school construction hardware bound students cannot meet the huge number of choices and so make our art and design education embarrassment. On the other hand, homogeneity inheritance of art and design education are more serious, which does different levels and in different regions of college, polytechnic schools, colleges and other social science professional art and design. It will inevitably result in different school level, the gap increases largely, and investment will lead to varying degrees of importance to the design professional. That is a huge number of students and schools that recognize difference that can cause a lot of pressure on our art and design education in the practice of teaching hardware construction, software, building and construction of teachers. Innovation is the soul of art and design, thinking and reflection on the basis of training needs and practices to enhance the process, you need to provide domestic and international investigations, field trips, the product of a strong purpose and strong support, which is not feasible. 


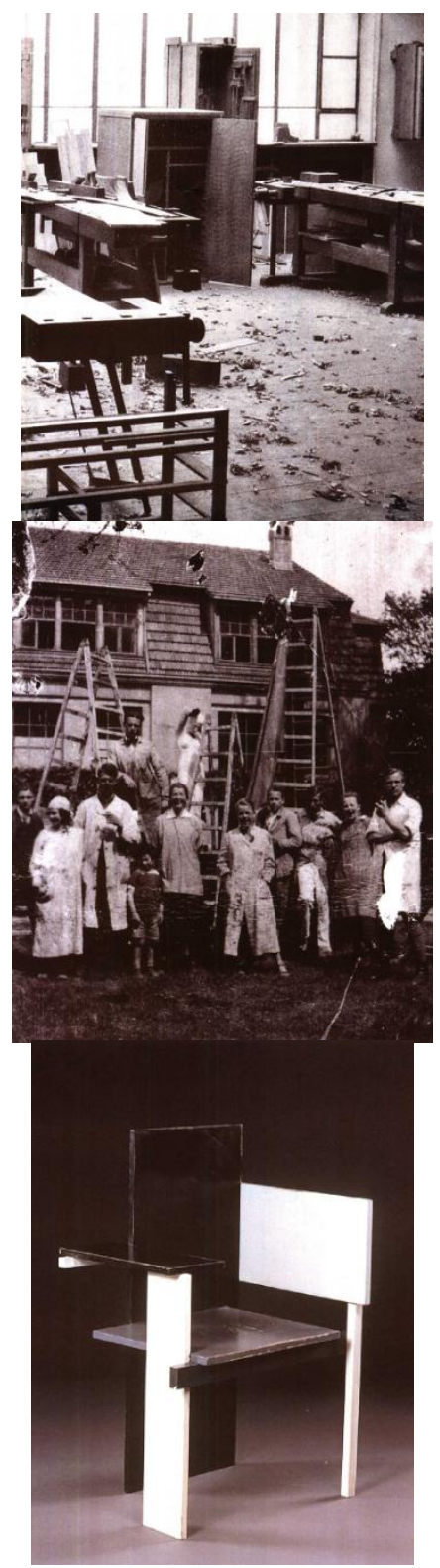

Figure 2 Students focus on the building outside the workplace in 1920. Berlin chair, Grit Reitveld design in 1923.

\section{APPROACH FRAMEWORK OF ART AND DESIGN PROFESSIONAL IN CLASSROOM WORKSHOP}

Research come from the perspective of the origin and development workshops, this model will be applied to classroom teaching direction that is still in the preliminary stage. In fact, it cannot escape the professional art, design, and construction of this model, because of the characteristics of art and design professionals that also need to practice exchange students or participants to promote a good way to self-study. Currently building workshops require further discussion, but we have reason to believe that this stems from education and psychology research of workshop ideas, which can have their own piece of the sky in the art and design professional. In the Nanjing Institute of the Arts
School of Design in 2012 "I / ME / MYSELF", Workshop Exhibition requires students in later designs to continue to find "new" elements and to apply their own design to work, and to maximize the mobilization ability to think independently and creativity. [7] Taiwan cultural and creative Foundation organized construction, glass, pottery, bamboo home, experience design, playing with paper, food, design, fun and participants can learn knowledge, are willing to participate. Looking to the future of art and design education, it will be to create diversity, integration, social environment, human values worth living in harmony with each other, we need to design the direction of education that must become experiment, research and development center, to promote the art and design education level of the highclass. [8] Domination of the future of art and design of specialized knowledge butted industry. but professional property should also be in conception, creation and on different spatial processes found with other theories, professional organic contact. The creation ability of a professional art and design is the core value, teacher-led art and design education will be the focus. And it must be reformed to promote communication, continuous practice, and promote conscious initiative to explore the establishment of appropriate practices around industrial development. Workshops mode is o art and design professionals that can focus on the future integration of research methods.

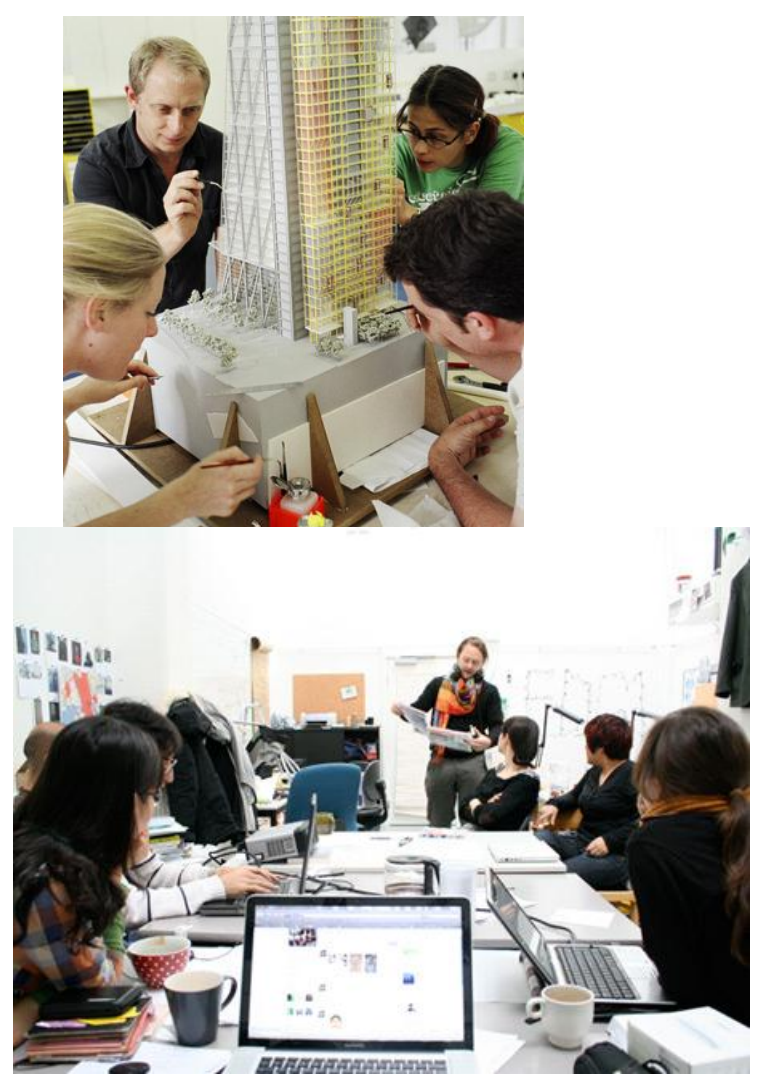

Figure 3 RSHP model design workshops, in English in2011. SMR Experience Design Workshop, in Sweden Konstfack College of Art and Design in 2011 
Frame workshop practice patterns mainly consist of theory, practice and experience of three aspects constitute (Table 1), such as theoretical research, dissertation research that belong to the theory. The British Architects RSHP (moving line Design Workshop), Communication University of China South Canton College Institute of Photography "workshop approach" belong to the class practice research experience. Konstfack College of Art and design in Sweden SMR (social media revolution) experience and design workshops of the cultural and creative Taiwan Foundation organized pottery and architecture etc. design belongs to experience workshops. In summary, the workshop approach helps to establish professional art and design that play a specific role with the times, geography, culture, tolerance, mental health, and economic development in the professional development and professional segments of classroom teaching process. At home and abroad, besides advanced features of art and design education, in addition to more in the future of attention and other technology, economy and culture of Chinese art and design education; we should pay attention to good ideas, innovation path.

Table 1 workshop practice model framework composition table

\begin{tabular}{|c|c|c|}
\hline Category & Direction & Property \\
\hline Theory class & $\begin{array}{l}\text { Macroeconomic theory, middle theory, microeconomic } \\
\text { theory }\end{array}$ & $\begin{array}{l}\text { Proposition and debate, } \\
\text { experience and summary }\end{array}$ \\
\hline Practice Class & $\begin{array}{l}\text { Experimental workshops, product research workshops, } \\
\text { product production workshops, product marketing } \\
\text { workshops, technology and new materials research and } \\
\text { development workshops, market research workshops, } \\
\text { regional and national cultural studies Workshops }\end{array}$ & $\begin{array}{l}\text { The integration of } \\
\text { technology, art, science, } \\
\text { economy, } \\
\text { innovation }\end{array}$ \\
\hline Experience & $\begin{array}{l}\text { experience studio of Specific project (such as } \\
\text { construction, animation, hand-painted renderings, etc.) }\end{array}$ & $\begin{array}{l}\text { By the Master, professionals } \\
\text { in the field, craftsmen, and } \\
\text { other nationalities in } \\
\text { different regions to } \\
\text { communicate with project }\end{array}$ \\
\hline
\end{tabular}

We cannot exclude oriented teacher education, but students are based on specialized research teacher before class is offered so that students can learn meaningful conscious, active process in theory, and they even modeled expert investigation method, classroom will be more vivid. Practice research methods class is more complicated, mainly fusion research must be the basis for other disciplines, such as architectural design research, design research building earthquake shock, the material elements of art and design experiments and so on. These things are more difficult, at present our country any professional design schools cannot say that his artistic practice of design is the most high-end, cutting-edge. [9] The practice of class workshop approach we need are to do further research in the classroom. The main professional development should be explored in conjunction with other disciplines of art and design curriculum courses. And the specific projects should be combined with those in need of specific studies like car manufacturing. Scientific analysis of market research can hardly see undergraduate art and design. such a number of research methods, and in the "opinions on the Ministry of Education and comprehensively to improve the quality of higher education" clearly states: we should support undergraduate students to participate in research activities, early into the issues, early into the laboratory, early into the team.

Experiential workshop approach, with a flexible, fun, inspiring and strong features therefore are the most likely to cause a workshop approach, but at the same time on the management of funds, the venue, the organizers have a greater requirement. General experience in the study of the process of teaching experience have different ways of education to their students to inspire students' thinking, the ability, communication and understanding, teamwork, etc., which is the result of individual and team. Spanish designer Nacho Carbonell's Harvest To Create (fantasy creation workshops), American designer Andrew Ondrejcak of Design And Performance (Design and Performance Workshop) and so reflect the interesting topics, there are specific characteristics of the direction of experiential workshops.

\section{CONCLUSIONS}

Art and design professional orientation are the primary preparatory work carried out before building workshop approach, each university has different school environment, history, resources that need to be with artistic vision system design with professional orientation, homogeneity tendency is mentioned earlier that we should avoid, and we cannot be made thousands of people face a professional layout. In the East or the West; whether art and design professionals in the north, south, such as different geographic areas should reflect on their own learning students in the future to establish a new image positioning, new ways. "Made in China" and "innovated in China" word, but we can see that our art and design innovation is not enough. Educating students in the classroom teaching art and design professionals is to address these issues that stand in the podium to explain the knowledge alone which is concerned, it does not allow students to think about these issues. College of Art and Design, in Tsinghua University on the current problems of design education, also noted several problems. There is a lack of professional interest of students; innovation is too superficial; the teachers do not have time of thinking and 
researching. Schools of thought and ideas, positioning is unclear; there is a lack of thinking and methods training and lack of social communication and other courses; imperfect evaluation system, which can be used to train and improve the model by building workshops. Workshop approach will not solve all issues raised, but we are on the road to art and design education in order thinking and theoretical innovation, unity of art and technology, materials and products combination, social awareness and the development of human body, as the establishment of a sound system based on workshop approach can provide a solution.

\section{References}

[1] Huang Yue. University of workshops teaching the teacher's role mode [J] Education \& Science University, 2011 (6): 56.

[2] People's Republic of China Ministry of Education, Ministry of Education Opinions on Improving Quality of Higher Education [EB / OL]
[3]Http://www.moe.edu.cn/publicfiles/business/htmlfiles/moe/A08_zcwj/20 1204/ 134370.html, 2012-3-16.

[4] (United Kingdom) Carmel - Arthur edited by Yan Fang translated Bauhaus [M] Beijing: China Light Industry Press, 2002: 10-11....

[5] The Chinese government network. Long-term Education Reform and Development Plan (2010-2020) [EB / OL]. Http://www.gov.cn/jrzg/2010-07/29/content_1667143.htm, 2010-7-29.

[6] Lu Hongmei. On the development of China's colleges of art and design education [J] CULTURE, 2011 (6): 87.

[7] Design College of Nanjing Arts Institute Design Institute organized "I / ME / MYSELF" Workshop Exhibition [EB / OL]. Http://dc.njarti.cn/s/38/t/654/4e/76 /info20086.htm,2012-4-9.

[8] Yu Qiang. Edited Introduction to Design Arts [M] Chongqing: Chongqing University Press, 2006: 191.

[9] Policy Research Group China Art Design Education Tsinghua University, China Art Design Education Development Strategy [M]. Beijing: Tsinghua University Press, 2010: 363-385. 